\title{
COMPARATIVE STUDY OF DEXMEDETOMIDINE AND FENTANYL TO OBTUND THE PRESSURE RESPONSE TO LARYNGOSCOPY AND INTUBATION.
}

\author{
Thapa $A S^{1^{*}}$, Yadav $R K^{1}$, Dhakal $B^{1}$
}

\section{Affiliation}

1. Lecturer, Department of Anesthesiology and critical care college of medical sciences and teaching hospital, Bharatpur, Chitwan, Nepal

2 Associate Professor, Department of Anesthesiology and critical care College of medical sciences and teaching hospital, Bharatpur, Chitwan, Nepal

3 Lecturer, Department of nursing College of medical sciences and teaching hospital, Bharatpur, Chitwan, Nepal

A R T I C L E I N F O
Article History
Received : 16 January, 2018
Accepted : 30 November, 2018
Published : 31 December, 2018

(c) Authors retain copyright and grant the journal right of first publication with the work simultaneously licensed under Creative Commons Attribution License CC - BY 4.0 that allows others to share the work with an acknowledgment of the work's authorship and initial publication in this journal.

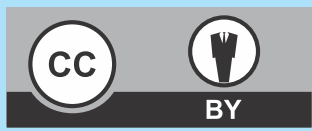

ORA 81

DOI: $10.3126 /$ bjhs.v3i3.22166

\author{
* Corresponding Author \\ Dr. Ajay Singh Thapa \\ College of Medical Sciences \\ Email: ajaysinghthapa567@gmail.com \\ ORCID: https://orcid.org/0000-0003-3196-9925
}

\section{Citation}

Thapa AS, Yadav RK, Dhakal B. Comparative Study of Dexmedetomidine and Fentanyl to Obtund the Pressure Response to Laryngoscopy and Intubation. BJHS 2018;3(3)7: 514-518

\section{ABSTRACT}

\section{Introduction}

Airway manipulation during endotracheal intubation is associated with hemodynamic and cardiovascular responses. Different agents have been used to obtund the pressure response.

\section{Objectives}

To evaluate the place of Dexmedetomidine for routine use during induction of anesthesia to blunt pressure response to laryngoscopy and intubation.

\section{Methodology}

One hundred patients of ASA I and II were randomly divided into two groups. Group A received Midazolam $(0.05 \mathrm{mg} / \mathrm{kg}$ ) and Fentanyl $(2 \mathrm{mcg} / \mathrm{Kg}$ ) andgroup $B$ received Dexmedetomidine $(0.6 \mathrm{mcg} / \mathrm{kg}) 10$ minutes before induction of anesthesia. Both groups were induced with Propofol ( $1.5 \mathrm{mg} / \mathrm{Kg}$ ). In all patients after induction (loss of eye lashes reflex) tracheal intubation was facilitated using Rocuronium $1 \mathrm{mg} / \mathrm{kg}$. Baseline heart rate was noted and hemodynamic response to intubation was observed 3,6 and 9 minutes after intubation.

\section{Results}

In group A, time for loss of eyelashes reflex was $17.45 \pm 2.19$ seconds and in group $B$ it was $11.33 \pm 2.64$ seconds. In group $A$, after intubation heart rate increased by $11.22 \pm 2.37$, $5.71 \pm 1.68,2.34 \pm 1.73$ in 3,6 and 9 minutes respectively. In group $A$, after intubation MAPincreased by $6.49 \pm 1.37$, $3.30 \pm 1.15$, and $1.24 \pm 1.50$ from baseline in 3,6 , and 9 minutes respectively.In group $B$ after intubation heart rate increased by $2.49 \pm 0.89$ from baseline at third minutes, however decreased by $2.85 \pm 1.58$ and $4.73 \pm 1.86$ at sixth and ninth minute respectively. In group B, MAP increased from baseline by $3.44 \pm 1.06$ in third minute however decreased by $2.22 \pm 1.38$ and $4.24 \pm 3.40$ at sixth and ninth minutes respectively.

\section{Conclusion}

Both the agents were observed to obtund pressure response to laryngoscopy and intubation however Dexmedetomidine proved to be better option compared to Fentanyl.

\section{KEYWORDS}

Dexmedetomidine, Fentanyl, Intubation, Laryngoscopy. 


\section{INTRODUCTION}

The pressure response to laryngoscopy and intubation is a sympathetic reflex that is provoked by stimulation of the oro-laryngopharynx. Manipulation of the respiratory tract such as in laryngoscopy and tracheal intubation are associated with hemodynamic and cardiovascular responses consisting of increased circulating catecholamine, heart rate, blood pressure, myocardial oxygen demand and dysrhythmias. ${ }^{1,2}$ In patients with cardiovascular and cerebrovascular diseases, this sudden rise in heart rate and blood pressure can produce deleterious effects in the form of myocardial ischemia, pulmonary edema and cerebral hemorrhage. ${ }^{3}$ Various drug regimens and techniques have been used from time to time for attenuating the stress response to laryngoscopy and intubation, including opioids, barbiturates, benzodiazepines, beta blockers, calcium channel blockers and vasodilators. With the easy availability of Dexmedetomidine in Nepalese market recently, this study was done to find the place of Dexmedetomidine for its daily use as a premedication to obtund the pressure response to laryngoscopy and intubation.

\section{OBJECTIVE}

To evaluate the place of Dexmedetomidine for routine use during induction of anesthesia to blunt pressure response to laryngoscopy and intubation.

\section{METHODOLOGY}

After approval from institutional review committee (IRC), prospective comparative study was conducted in the Department of Anesthesiology, College of Medical Sciences, Bharatpur, Chitwan, Nepalfrom February 2017 to July 2017.

One hundred ASA I and II patients aged $18-45$ years old, posted for elective surgery under general anesthesia were included. Patients who were ASA more than II, aged less than 18 or more than 45 years, predicted difficult laryngoscopy and intubation, posted for emergency surgery, heart rate more than 100 or less than 50 , grade III hypertension or blood pressure less than $90 / 60 \mathrm{mmofHg}$ were excluded from the study.

Sample size calculation was based on the study by sulaimanet $\mathrm{al}^{4}$. Standard deviation and difference between the means were taken from the mean heart rate at three minutes after intubation.

The sample size was calculated by using the following formula:

$$
\begin{aligned}
\text { Where } & \quad \mathrm{n}>\frac{2(\mathrm{Z} \alpha+\mathrm{Z} \beta)^{2} \times \mathrm{SD}^{2}}{\mathrm{~d}^{2}} \\
\mathrm{n}= & \text { Number of sample } \\
\mathrm{Z} \alpha= & 1.96 \text { (constant at given alpha error) } \\
\mathrm{Z} \beta= & 1.282 \text { (constant at given beta error) } \\
\mathrm{SD}= & \text { Sum of standard deviation of the two groups } \\
& \text { which is } 20.1 \text { from previous study } \\
\mathrm{d}= & \begin{array}{l}
\text { Difference of mean between two groups which } \\
\text { is } 14.54
\end{array}
\end{aligned}
$$

The sample size in each group comes to be $>40.11$. We decided to take 50 patients in each group. Therefore the total sample size was taken as 100 in our study.

Patients were assigned into two equal groups of 50 patients $(n=50)$ using. Group A received Midazolam $(0.05 \mathrm{mg} / \mathrm{kg}$ ) and Fentanyl $(2 \mathrm{mcg} / \mathrm{Kg})$ and group $B$ received Dexmedetomidine $(0.6 \mathrm{mcg} / \mathrm{kg})$. Premedication was done 10 minutes before induction of anesthesia. ${ }^{5}$ Preoxygenation with 100 percent oxygen for three minutes was done in both the groups followed by induction with intravenous Propofol $(1.5 \mathrm{mg} / \mathrm{Kg}$ ) over 20 seconds. Induction time was taken as the time in seconds from the start of injection to disappearance of eyelashes reflex. In all patients after induction (loss of eye lashes reflex) tracheal intubation was facilitated using Rocuronium $1 \mathrm{mg} / \mathrm{kg}$. All the patients were intubated after 90 seconds of injecting Rocuronium with appropriate size tube. Baseline heart rate was noted and hemodynamic response tointubation was observed at 3,6 and 9 minutes after intubation. Exaggerated response to intubation i.e fluctuation of heart rate and mean arterial pressure greater than or less than 20 from baseline value were managed with deepening anesthesia with intravenous Propofol and intravenous Esmolol $0.25 \mathrm{mg} / \mathrm{kg}$ if required. Patients who had exaggerated response were excluded from the study. Group B patients received intravenous Fentanyl $2 \mathrm{mcg} / \mathrm{kg}$ after 10 minutes of intubation and at least 5 minutes before surgical incision. Anesthesia was maintained with oxygen and Isoflurane. Whenever required, Fentanyl for analgesia and Vecuronium or Rocuronium for muscle relaxation was added intraoperatively. Statistical analysis was done using independent $t$ test for loss of eyelashes reflex and paired $t$ test for comparing mean value of heart rate and mean arterial blood pressure with IBM SPSS statistics version 20 software.

\section{RESULTS}

Demographic profile of the patients included in the study is listed in table 1. In group A, time for loss of eyelashes reflex was $17.45 \pm 2.19$ seconds and in group $B$ it was $11.33 \pm 2.64$ seconds. It was seen that patients in group $B$ were induced faster compared to group $A$. The difference between the two groups was statistically significant $(p<0.05)$. As shown in figure 1 and table 2, baseline heart rate in group $A$ was $80.14 \pm 8.61$ which after intubation increased by $11.22 \pm 2.37$ in three minutes, by $5.71 \pm 1.68 \mathrm{in}$ six minutes and by $2.34 \pm 1.73$ in 9 minutes. Heart rate was observed to increase in all three readings which were statistically significant $(p<0.05)$. Baseline heart rate in group $B$ was $78.27 \pm 7.63$ which after intubation increased by $2.49 \pm 0.89$ however decreased by $2.85 \pm 1.58$ at sixth minute and by $4.73 \pm 1.86$ at ninth minute, from the baseline which were statistically significant $(p<0.05)$. As shown in figure 2 and table 3 , in group A, baseline MAP (mean arterial pressure) was 83.96 \pm 8.99 which after intubation increased by $6.49 \pm 1$.37in three minutes, by $3.30 \pm 1.15$ in six minutes and by $1.24 \pm 1.50$ in nine minutes, from the baseline which were statistically significant $(p<0.05)$. In group $B$, baseline MAP was 
$84.04 \pm 8.29$ which increased by $3.44 \pm 1.06$ in third minute however it was observed that MAP decreases by $2.22 \pm 1.38$ at sixth minute and by $4.24 \pm 3.40$ at ninth minute which were statistically significant.

Table 1: Demographic profile of the population included in the study.

\begin{tabular}{|l|c|c|}
\hline & Group A (No.:50) & Group B (No.:50) \\
\hline Age & $29.64 \pm 6.79$ & $32.20 \pm 7.05$ \\
\hline Sex (M:F) & $27: 23$ & $31: 19$ \\
\hline ASA (I:II) & $38: 12$ & $36: 14$ \\
\hline
\end{tabular}

Table 2: Comparison of heart rate between two groups.

\begin{tabular}{|l|c|c|}
\hline Heart rate & $\begin{array}{c}\text { Fentanyl } \\
\text { Group }\end{array}$ & $\begin{array}{c}\text { Dexmedetomidine } \\
\text { Group }\end{array}$ \\
\hline Baseline & $80.14 \pm 8.61$ & $78.27 \pm 7.63$ \\
\hline Three minutes & $91.37 \pm 8.84$ & $80.76 \pm 7.52$ \\
\hline Six minutes & $85.86 \pm 8.57$ & $75.4 \pm 7.64$ \\
\hline Nine minutes & $82.49 \pm 8.24$ & $73.53 \pm 7.24$ \\
\hline
\end{tabular}

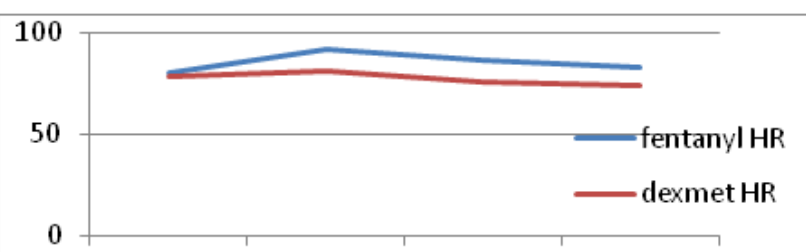

Baseline 3 minutes 6 minutes 9 minutes

Figure 1: Pattern of Heart rate before and after intubation.

Table 3: Comparison of Mean Arterial Pressure between two groups.

\begin{tabular}{|c|c|c|}
\hline & Fentanyl & Dexmedetomidine \\
\hline Baseline & $83.96 \pm 8.99$ & $84.04 \pm 8.29$ \\
\hline Three minutes & $90.45 \pm 8.74$ & $87.49 \pm 8.21$ \\
\hline Six minutes & $87.27 \pm 8.86$ & $81.82 \pm 8.04$ \\
\hline Nine minutes & $85.20 \pm 8.72$ & $79.80 \pm 8.48$ \\
\hline
\end{tabular}

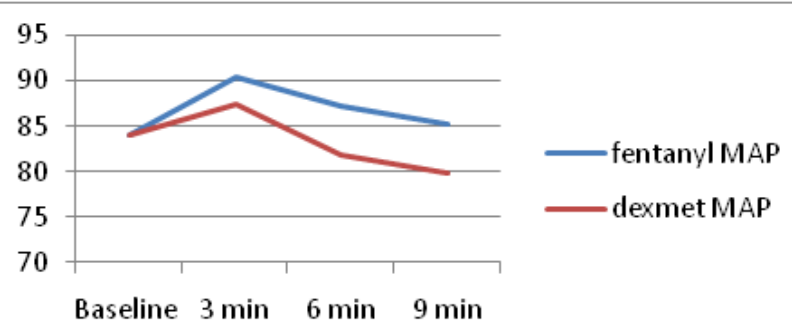

Figure 2: Pattern of Mean arterial blood pressure before and after intubation.

\section{DISCUSSIONS}

Laryngoscopy and endotracheal intubation is often associated with hypertension and tachycardia because of the sympatho-adrenal stimulation which is usually transient and lasts for 5 to 10 minutes which can result in deleterious events in patients with cardiovascular and cerebrovascular conditions. ${ }^{6}$ The mechanism through which laryngoscopy and intubation increases blood pressure and heart rate are proposed to be by somatovisceral reflexes. During laryngoscopy, stimulation of proprioceptors at the base of the tongue increases catecholamine concentration, blood pressure and heart rate. Endotracheal intubation results in stimulation of additional receptors resulting in further increase in catecholamine concentration. ${ }^{7}$ Different studies have been done with other agents to abolish the hemodynamic effects of laryngoscopy and intubation. Opioids are excellent agents for depressing upper airway, tracheal, and lower respiratory tract reflexes but the mechanism is not clear. Opioids allow patients to tolerate endotracheal tubes without coughing or bucking. Fentanyl is the most commonly studied drugs to attenuate hemodynamic response to laryngoscopy and tracheal intubation. Fentanyl is a completely synthetic $\mu$ receptor stimulating opioid. ${ }^{8}$ Fentanyl suppresses the hemodynamic responses to endotracheal intubation more than it does to laryngoscopy. ${ }^{9}$ Fentanyl supplementation with lower dose ( $2 \mathrm{mcg} / \mathrm{kg}$ ) significantly attenuates the arterial pressure and heart rate increases during laryngoscopy and intubation, and Fentanyl, at higher dose $(6 \mathrm{mcg} / \mathrm{kg})$, completely abolishes these responses. However, higher doses of any opioid can aggravate induction hypotension, risk for respiratory depression and need for postoperative mechanical ventilation. ${ }^{10}$

Dexmedetomidine, the pharmacologically active d-isomer of medetomidine is a highly specific and selective alpha-2 adrenoreceptor agonist which is gaining popularity for its sympatholytic, sedative, anaesthetic sparing and hemodynamicstabilizing properties without significant respiratory depression. ${ }^{11}$ Dexmedetomidine attenuates sympathoadrenal response to tracheal intubation and reduces perioperative anaesthetic requirement. Locus ceruleus of the brain stem and spinal cord are the principal site of action. It decreases sympathetic response to airway instrumentation and thus minimizes changes in blood pressure and heart rate during laryngoscopy and intubation. ${ }^{12}$ Premedication dose of Dexmedetomidine is 0.33 to 0.67 $\mathrm{mcg} / \mathrm{kg}$. This dose of Dexmedetomidine minimizes side effects of hypotension and bradycardia. For procedural sedation usual dose is $1 \mathrm{mcg} / \mathrm{kg}$ followed by 0.2 to 1.4 $\mathrm{mcg} / \mathrm{kg} / \mathrm{hr}^{13}$

Perioperative arrhythmias especially atrial fibrillations are common complications following cardiac surgeries. Dexmedetomidine is a highly selective and potent $\alpha 2$ adrenoreceptor agonist which along with analgesic and anaesthetic effects also has other beneficial effects including reduction in the release of catecholamine. Similar to adults, it has been observed that Dexmedetomidine usage in children led to more stable intraoperative hemodynamics, less duration of postoperative mechanical ventilation, analgesic requirement and over all hospital stay. Gong et al $^{14}$ conducted a meta-analysis and systemic review on myocardial protective effects Dexmedetomidine in patients undergoing cardiac surgery. They observed that perioperative use of Dexmedetomidineimproves heart rate, systolic blood pressure and lowers the chances of arrhythmias, but it also increases the incidence of bradycardia, indicating particular attention in cases with shock and transduction block. They also observed that 
group of patients who received perioperative Dexmedetomidine required shorter duration of mechanical ventilation, had shorter duration of Intensive care unit stay and shorter duration of hospital stay.

Adrenergic response especially hypertension during laryngoscopy and intubation in neurosurgical patients may result in increase in intracranial pressure, intracranial bleed and adverse hemodynamic effects which may increase the morbidity in suchpatients and prolonged hospital stay. Preventing andcontrolling these hemodynamic adverse events during airway manipulation in neurosurgery patients is of paramount importance to preserve the cerebral homeostasis.Srivastavaet $\mathrm{al}^{15}$ in a comparative study with Dexmedetomidine and Esmolol,to evaluate hemodynamic response to laryngoscopy and intubation in neurosurgery patients, observed that Dexmedetomidine was equivalent to Esmolol in controlling surge in heart rate during intubation. However, they observed that systolic blood pressure and mean arterial blood pressure were statistically lower in Dexmedetomidine group than esmolol group.

Pokhrel et al ${ }^{16}$ conducted a randomized placebo controlled study in which they observed that mean arterial pressure and heart rate were comparable in both study and control group after induction but during laryngoscopy, intubation and then after the differences in both parameters were statistically significant. They observed that Dexmedetomidine at $1 \mathrm{mcg} / \mathrm{kg}$ given 10 minutes prior to endotracheal intubation significantly attenuates heart rate and mean arterial pressure at 1,3 and 5 minutes compared to placebo. They concluded that Dexmedetomidine at 1 $\mathrm{mcg} / \mathrm{kg}$ is devoid of any complications and is safe as a premedication in ASA I and II patients to attenuate response to laryngoscopy and intubation.

In our study, we observed that patients in group B were induced faster compared to group $A$. Difference of eyelashes reflex in two groups was $6.12 \pm 3.47$ seconds which was statistically significant $(p<0.05)$.Sulaiman et $\mathrm{al}^{4}$ observed that patients premedicated with Dexmedetomidine were induced faster compared to those who received Midazolam and Fentanyl which was statistically significant $(p<0.05)$. Similar to our observation, Senapatiet al $^{17}$, who conducted a double blinded randomized controlled study observed that Dexmedetomidine decreases Propofol requirement during induction of anesthesia.

In our study we observed that increase in heart rate (HR) gradually decreased towards baseline in Fentanyl group and below baseline in Dexmedetomidine group. The differences in heart rate from the baseline in both the groups at third, sixth and ninth minute were statistically significant $(p<0.05)$. In group $A$, heart rate after intubation increased by $11.22 \pm 2.37,5.71 \pm 1.68$ and $2.34 \pm 1.73$ at 3,6 and 9 minutes respectively. Heart rate was observed to increase in all three readings which were statistically significant $(p<0.05)$. Baseline heart rate in group $B$ was $78.27 \pm 7.63$ which after intubation increased by $2.49 \pm 0.89$ $(p<0.05)$. However, it was observed that heart rate was decreased by $2.85 \pm 1.58$ at sixth minute and by $4.73 \pm 1.86$ at ninth minute, from the baseline which were statistically significant $(p<0.05)$. Saraf et $a^{6}$ in a randomized controlled study, in which study group received $0.6 \mathrm{mcg} / \mathrm{kg}$ Dexmedetomidine, observed that the mean HR decreased by 2.68 beats/min from the baseline value. They concluded that Dexmedetomidine given 10 minutes prior to induction is effective in attenuating the pressure response to laryngoscopy and tracheal intubation without any side effects. In another randomized double blind prospective study by mondalet $\mathrm{al}^{18}$, where they compared Dexmedetomidine with Fentanyl during fiberoptic bronchoscopy, they observed that there was no significant changes in heart rate and blood pressure after premedication in both the groups. There was a significant change of HR in the post-intubation period in comparison with the baseline value in Fentanyl group. However, there was no significant changes of HR in the post-intubation period in comparison with baseline value in Dexmedetomidine group.

In our study, we observed that mean arterial blood pressure (MAP) increases in the third minute which gradually decreased towards baseline but remained above the baseline in Fentanyl group and decreased below the baseline in Dexmedetomidine. The differences in mean arterial pressure from the baseline in both the groups at third, sixth and ninth minute were statistically significant $(p<0.05)$. In group A, baseline MAP was $83.96 \pm 8.99$ which after intubation increased above the baseline by $6.49 \pm 1.37$, $3.30 \pm 1.15$ and $1.24 \pm 1.50$ in 3,6 and 9 minutes. All the three readings were higher compared to baseline value and statistically significant $(p<0.05)$. In group $B$, baseline MAP was $84.04 \pm 8.29$ which increased by $3.44 \pm 1.06$ in third minute $(<0.05)$. However, it was observed that MAP decreases by $2.22 \pm 1.38$ at sixth minute and by $4.24 \pm 3.40$ at ninth minute which were statistically significant. Gandhi et $\mathrm{al}^{19}$ observed that the mean arterial blood pressure increases significantly from the baseline during intubation but the increase was highly significant in Fentanyl group as compared to Dexmedetomidine group during laryngoscopy and after intubation. Similar to our study, Gandhi et al observed that Dexmedetomidine tends to decrease mean arterial pressure compared to Fentanyl which was statistically significant. In aa similar study by Ozairet al $^{20}$, they observed Dexmedetomidine group, they observed blood pressure was maintained at lower values even after intubation. Similar to our study, they concluded that Dexmedetomidine was better than Fentanyl to obtund pressure response to intubation.

In our study it was observed that Dexmedetomidine tends to obtund adrenergic response to intubation better than Fentanyl. It was observed that at three minutes heart rate and blood pressure where above the baseline in both the groups and gradually decreased towards baseline in Fentanyl group and below the baseline in Dexmedetomidine. The observations were statistically significant. 


\section{CONCLUSION}

Fentanyl is a good choice for premedication prior to laryngoscopy and intubation but Dexmedetomidinecan be a better alternativeto obtund the pressure response to airway manipulation.

\section{LIMITATIONS OF THE STUDY}

This study was conducted without a control group in small population and does not represent high risk patients i.e ASA $>$ II.

\section{REFERENCES}

1. Fassoulaki A, Melemeni A, Paraskeva A et al. Gabapentin attenuates the pressor response to direct laryngoscopy and tracheal intubation. BJA 2006;96:769-73.

2. Matot I, Sichel J, Yofe $V$ et al. The effect of clonidine premedication on hemodynamic responses to microlaryngoscopy and rigid bronchoscopy. AnesthAnalg 2000;91:828-33.

3. Saraf $R$, Jha $M$, Kumar $S$ et al. Dexmedetomidine the ideal drug for attenuating pressorresponse.PACCJ2013;1(1):78-86.

4. Sulaiman S, Karthekeyan RB, Vakamudi M, Sundar AS, Ravullapalli $H$, Gandham R. The effects of Dexmedetomidine on attenuation of stress response to endotracheal intubation in patients undergoing elective off-pump coronary artery bypass grafting. Ann Card Anaesth 2012;15:39-43.

5. Nath MP, Singh BK, Garg R et al. To compare the hemodynamic changes with single dose of intravenous Dexmedetomidine versus Midazolam. J AnesthCrit Care 2015;2(1):1-6.

6. Saraf R, Jha M, Kumar S, Damani K, Bokil S, Galante D. Dexmedetomidine the ideal drug for attenuating the pressorresponse.PACCJ2013;1(1):78-86.

7. Arora S, Kularkarni A, Bhargava AK. Attenuation of hemodynamic response to laryngoscopy and orotracheal intubation using intravenous clonidine. J AnaesthesiolClinPharmacol 2015;31:110-4.

8. Stanley TH. The Fentanyl story. Jpain2014;15:1215-26.

9. Adachu YU, Satomoto M, Higuchi H, Watanabe K. Fentanyl attenuates the hemodynamic responses to endotracheal intubation more than the response to the response to laryngoscopy. AnaesthAnalg2002;95(1):233-7.

10. Kautto UM. Attenuation of the circulatory response to laryngoscopy and intubation by Fentanyl. ActaAnaesthesiologicaScandinavica 1982;26(3):217-21.

11. Savola JM, Ruskoaha H, Puurunen J, Salonen JS, Karki NT. Evidence for medetomidine as a selective and potent agonist at alpha-2 adrenoreceptors. J Autonomic Pharmacol1986;5:275-84.

\section{RECOMMENDATION}

This study is only able to compare Dexmedetomidine and Fentanyl for obtunding response to intubation and not able to compare Dexmedetomidine as an sole alternative to Fentanyl for a surgical procedure. Further studies on combination of these two agents needs to be performed.

12. Keniya VM, Ladi S, Nephade R. Dexmedetomidine attenuates sympathoadrenal response to tracheal intubation and reduces perioperative anaesthetic requirement. Indian J Anaesth 2011;55(4):352-7.

13. Kaur $M$, Singh PM. Current role of Dexmedetomidine in clinical anesthesia and intensive care.Anesth Essays Res 2011;5:128-33.

14. Gong, Z., Ma, L., Zhong, Y., Li, J., Lv, J., \&Xie, Y. Myocardial protective effects of Dexmedetomidine in patients undergoing cardiac surgery: A meta-analysis and systematic review. Experimental and Therapeutic Medicine 2017;13: 2355-61.

15. Srivastava VK, Agrawal S, Gautam SS, Ahmed M, Sharma S, Kumar R. Comparative evaluation of esmolol and Dexmedetomidine for attenuation of sympathomimetic response to laryngoscopy and intubation in neurosurgical patients. J AnaesthesiolClinPharmacol 2015;31:186-90.

16. Pokhrel N, Bajracharya UB. Attenuation of hemodynamic response to laryngoscopy and endotracheal intubation with Dexmedetomidine: a randomized controlled trial. JSAN 2016;3:28-31.

17. SenapatiLK,Samanta P. effect of Dexmedetomidine on dose requirement of Propofol and thiopentone induction in patients under general endotracheal anesthesia. Asian Journal of Pharmaceutical and Clinical Research 2018; 262-5.

18. Mondal S, Ghosh S, Bhattacharya S, Choudhary B, Mallick S, Prasad A. Comparison between Dexmedetomidine and Fentanyl on intubation conditions during awake fiberopticbronchoscopy.JOACP 2015;31(2):212-6.

19. Gandhi S, Goyal V, Radhakrishnan K, Balakrishnan M. Comparison of Dexmedetomidine with Fentanyl in attenuation of pressor response during laryngoscopy and intubation.IOSR Journal of pharmacy 2014;4(2):28-38.

20. OzairE, Ali QE, SiddiqueMd, Amir SH. A comparative evaluation of Dexmedetomidine and Fentanyl to attenuate hemodynamic response to laryngoscopy and intubation. AJMS 2018;9:1. 